SECTION 8. Architecture and construction.

Mikhail Egorovich Zayakhanov

Professor, Doctor of Technical Sciences,

East-Siberian State University of Technologies and Management, Russia

zayakhanov@mail.ru

\title{
USE OF EFFUSIVE ROCKS OF TRANSBAIKALIA FOR BUILDING MATERIALS
}

Abstract: The article discusses the possibility of use of effusive rocks of Transbaikalia for obtaining building materials. The basic properties of the received binders and concrete are given.

Key words: effusive rocks, binders, concrete, lime-perlitic binders.

Citation: Zayakhanov ME (2014) USE OF EFFUSIVE ROCKS OF TRANSBAIKALIA FOR BUILDING MATERIALS. ISJ Theoretical \& Applied Science 9 (17): 79-81. doi: http://dx.doi.org/10.15863/TAS.2014.09.17.13

\section{ИСПОЛЬЗОВАНИЕ ЭФФУЗИВНЫХ ПОРОД ЗАБАЙКАЛЬЯ ДЛЯ ПОЛУЧЕНИЯ СТРОИТЕЛЬНЫХ МАТЕРИАЛОВ}

\begin{abstract}
Аннотация: В статье рассмотрена возможность использования эффузивных пород Забайкалья для получения строительных материалов. Приведены основные свойства полученных вяжущих материалов и бетонов.
\end{abstract}

Ключевые слова: эфрфузивные горные породы, вяжущче вещества, бетоны, известково-перлитовые вяжущче.

Практически неограниченные запасы природного алюмосиликатного сырья на территории Восточной Сибири, к числу которых относятся перлитовые породы, цеолиты, вулканические шлаки и др., служат сырьем для производства многих материалов и изделий, в том числе для получения эффективных малоэнергоемких вяжущих материалов и бетонов на их основе [1, с. 12-17].

Из Забайкальских месторождений перлитовых пород наиболее разведанными являются Мухор-Талинская группа, Закультинская, Приаргунская, Холинская группы с общим запасом кондиционного сырья более 50 млн.т. [2, с. 34-36]. Строительнотехнические свойства природных цеолитов определяют целесообразность вовлечения их для получения строительных материалов и изделий. На территории Бурятии находится крупное Хурай-Цакирское месторождение вулканических шлаков. Уникальность вулканических шлаков заключается в том, что в отличие от всех других типов эффузивных пород они, благодаря своему активному химическому и фазовому составу, а также физической структуре, применимы для использования в двух видах: в виде компонента вяжущих веществ и в виде пористого заполнителя [2, с. 36-37].

Разработки в этом направлении и их реализация позволяют создавать теплоизоляционные, конструкционно-теплоизоляционные материалы и изделия с улучшенными механическими и теплофизическими свойствами.

С использованием вышеперечисленного природного алюмосиликатного сырья перспективны разработки известково-кремнеземистых вяжущих веществ, представляющих продукт помола негашеной извести и кремнеземистых компонентов и щелочных силикатных вяжущих. Для интенсификации твердения последних требуется введение щелочного компонента (жидкое стекло, силикат-глыба и др.), что позволяет получать бесклинкерные вяжущие по типу шлакощелочных [2, с.46-50].

Разработаны составы и исследованы основные свойства известково- перлитовых вяжущих материалов (табл. 1). 
Таблица 1

\section{Свойства известково- перлитовых вяжущих веществ}

\begin{tabular}{|c|c|c|c|c|c|}
\hline \multirow{2}{*}{$\begin{array}{c}\text { Содержание стеклофазы в } \\
\text { перлите, \% по массе }\end{array}$} & \multicolumn{5}{|c|}{$\begin{array}{c}\text { Предел прочности при сжатии (МПа) при содержании } \\
\text { активной } \mathrm{CaO}, \% \text { по массе }\end{array}$} \\
\hline & 10 & 15 & 20 & 25 & 30 \\
\hline 95 & $32 / 25$ & $48 / 38$ & $55 / 45$ & $43 / 40$ & $40 / 36$ \\
\hline 75 & $30 / 22,5$ & $45 / 32,6$ & $51 / 41$ & $42 / 31,5$ & $38 / 28$ \\
\hline 55 & $31 / 13$ & $43 / 25$ & $48 / 39$ & $42 / 19$ & $35 / 15,6$ \\
\hline 25 & $25,5 / 10$ & $41 / 16,5$ & $45 / 21$ & $40 / 14,5$ & $33 / 10$ \\
\hline 5 & $25 / 7$ & $39 / 12,5$ & $44,5 / 15$ & $39 / 12$ & $30 / 9$ \\
\hline
\end{tabular}

Примечание: над чертой результаты автоклавированных образцов ( $\mathrm{P}=1 \mathrm{MПа,} \tau=$ $2+8+2$ ч.); под чертой результаты пропаренных образцов $\left(\mathrm{t}=95^{\circ} \mathrm{C}, \tau=1,5\right.$ ч.)

Прочность известково-перлитовых вяжущих находится в прямой зависимости от степени остеклованности перлитовых пород. Высокая прочность вяжущих получена на основе перлитовых пород с содержанием стеклофазы 75-95\% не только при автоклавировании, но и при пропаривании. Для снижения водовяжущего отношения в процессе помола известково- перлитовых вяжущих вводили суперпластификатор С-3. Введение суперпластификатора позволило снизить содержание воды на 16- 25 \%, при этом прочность возросла до 40-50 МПа после пропаривания.

Была рассмотрена возможность получения известково-цеолитовых вяжущих измельчением в вибрационной мельнице с использованием цеолитов различных месторождений. Повышенные физико-механические свойства известково-цеолитовых вяжущих веществ достигаются за счет прессования полусухих масс и пластифицирования, что подтверждается проведенными экспериментами [2, с.87-92].

Оценка активности известково - кремнеземистых вяжущих веществ указывает на более высокие показатели их прочности при содержании 25-30 \% извести, 65-70 \% кремнеземистого компонента и 4-6\% двуводного гипса (\% по массе). Для повышения химической активности алюмосиликатных материалов использовалось измельчение вяжущих в различных аппаратах (шаровая, планетарная и вибрационная мельницы, дезинтегратор и др.) в сухом виде и в присутствии воды, а также электромагнитная активация [3; 4, с. 41-44]. Активация вяжущих веществ позволяет перейти с автоклавной обработки на безавтоклавную, при этом гидромеханическая активация позволяет использовать некондиционную известь (содержание пережога более 30 \%) [5, с. 56-58 ].

Исследование активности активированных алюмосиликатных вяжущих показало, что оптимальное содержание щелочного активатора составляет 9-11 \%, при этом обеспечиваются улучшенные физико - механические свойства.

Проведены экспериментальные работы по управлению синтезом бетонов на основе известково-кремнеземистых вяжущих веществ, разрабатываются теоретические основы оптимизации и направленного регулирования структуры строительных материалов в зависимости от заданных параметров по теплозащите и сейсмостойкости зданий и сооружений [6, с. 22-24].

На основе разработанных вяжущих веществ получены автоклавные и пропаренные бетоны: 


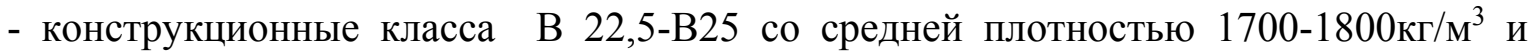
морозостойкостью 150 циклов;

- конструкционно-теплоизляционные класса В3,5-B7,5 со средней плотностью $1200 \kappa г / \mathrm{M}^{3}$ и морозостойкостью 25 циклов;

- теплоизляционные класса В2 со средней плотностью 400-500 теплопроводностью $0,1-012 \mathrm{BT} / \mathrm{M}^{\circ} \mathrm{C}$ [7, с.2-3].

Производство строительных материалов, изделий и конструкций на основе смешанных вяжущих веществ с использованием активированных перлитов, вулканических шлаков, цеолитов, а также модификация заполнителей физическими и химическими методами позволят снизить энергетические затраты при их получении по сравнению с традиционными на портландцементе [8, с. 159-164; 9, с. 27-29; 10, с. 9-10].

Применение разработанных вяжущих веществ и бетонов, изделий и конструкций на их основе при строительстве зданий и сооружений, возводимых в условиях высокой сейсмичности и суровых климатических условий (к таким регионам относится Восточная Сибирь), рационально вследствие уменьшения сейсмических нагрузок, как из-за возможного снижения массы зданий на 25-35\%, так из-за повышенной их способности к рассеиванию энергии сейсмических колебаний.

\section{References:}

1. Petrov VP, Nasedkin VV (1961) Perlit i drugie kislye prirodnye vulkanicheskie stekla kak gornye porody i promyshlennoe syr'e. Trudy IGEM, Moscow, No.48, pp. 51.

2. Cyrempilov AD, Zayakhanov ME, Hardaev PK, Hamaganov SD (1999) Effektivnye vyazhuschie i betony na osnove effuzivnyh porod. Ulan-Udie, Izd-vo BNC SO RAN, pp. 348.

3. Ubeev AV, Cyrempilov AD, Zayakhanov ME, Chimitov AZ (1991) Sposob prigotovleniya betonnoy smesi. Patent No.1636406, byull. No. 11.

4. Zayakhanov ME (1997) Snizhenie energeticheskih zatrat pri poluchenii stroitel'nyh materialov. Teoreticheskie osnovy stroitel'stva. Sb. statey 6 Rossiysko- pol'skogo seminara. Varshava, pp. 41- 44.

5. Cyrempilov AD, Zayakhanov ME, Hardaev PK, Damdinova DR (2005) Materialy na osnove mineral'nogo syr'ya. Stroitel'nye materialy, prilozh, No. 3, pp. 56-58.

6. Urhanova LA, Zayakhanov ME (2006) Vyazhuschie i betony na osnove vulkanicheskih shlakov. Stroitel'nye materialy No.7, pp. 22-24.

7. Dashicyrenov DD, Zayakhanov ME, Urhanova LA (2007) Effektivnyy penobeton na osnove ieffuzivnyh porod. Stroitel'nye materialy, No. 4, pp. 2-3.

8. Urhanova LA, Hardaev PK, Zayakhanov ME (2009) Stroitel'nye materialy s ispol'zovaniem effuzivnyh porod Zabaykal'ya. Vestnik MGSU, No. 3, pp. 159-164.

9. Zayakhanov ME, Berezovskiy PV, Balhanova ED (2011) Energeticheskoe sostoyanie effuzivnyh porod i energosberezhenie. Novye ienergo-i resursosberegayuschie naukoemkie tehnologii v proizvodstve stroitel'nyh materialov: sb. statey nauchno-tehn. konf. Penza, pp. 27-29.

10. Gorlov UP, Merkin AP (1980) Teploizolyacionnye materialy na osnove vulkanicheskih porod. Stroitel'nye materialy, No. 9, pp. 9-10. 